\title{
Accelerating Electro-Oxidation Turnover Rates via Potential-Modulated Stimulation of Electrocatalytic Activity
}

Alex M. Román ${ }^{1,2}$, Taylor D. Spivey ${ }^{1,2}$, Will Medlin ${ }^{1,2}$, and Adam Holewinski1 ${ }^{1,2 *}$

${ }^{1}$ Department of Chemical and Biological Engineering and ${ }^{2}$ Renewable and Sustainable Energy Institute, University of Colorado, Boulder, Colorado 80309, United States

Supplemental Information Contents:

1. Heat maps showing cycle-averaged currents during the final $60 \mathrm{~s}$ of a 360 s experiment in the presence of $0.1 \mathrm{M}$ formic acid at $\mathrm{E}_{\mathrm{DC}}=0.4-0.8 \mathrm{~V}_{\mathrm{RHE}}$

2. Heat maps showing cycle-averaged currents during the final 60 s of a 360 s experiment in the presence of no formic acid at $\mathrm{E}_{\mathrm{DC}}=0.4-0.8 \mathrm{~V}_{\mathrm{RHE}}$

3. Comparison between gas-chromatography predicted current and cycle-averaged currents conducted in a gas-tight batch cell.

4. Complete experimental results during the cycle-averaged oxidation of formic acid using PSEA methods at a variety of $A$ and $f$ values over 3600 s

5. Heat maps showing simulated, cycle-averaged attributes the presence of $0.1 \mathrm{M}$ formic acid at $\mathrm{E}_{\mathrm{DC}}=0.4-0.7 \mathrm{~V}_{\mathrm{RHE}}$ 


\section{Heat maps showing cycle-averaged currents during the final $60 \mathrm{~s}$ of a $360 \mathrm{~s}$ experiment in}

the presence of $0.1 \mathrm{M}$ formic acid at $\mathrm{E}_{\mathrm{DC}}=0.4-0.8 \mathrm{~V}_{\mathrm{RHE}}$
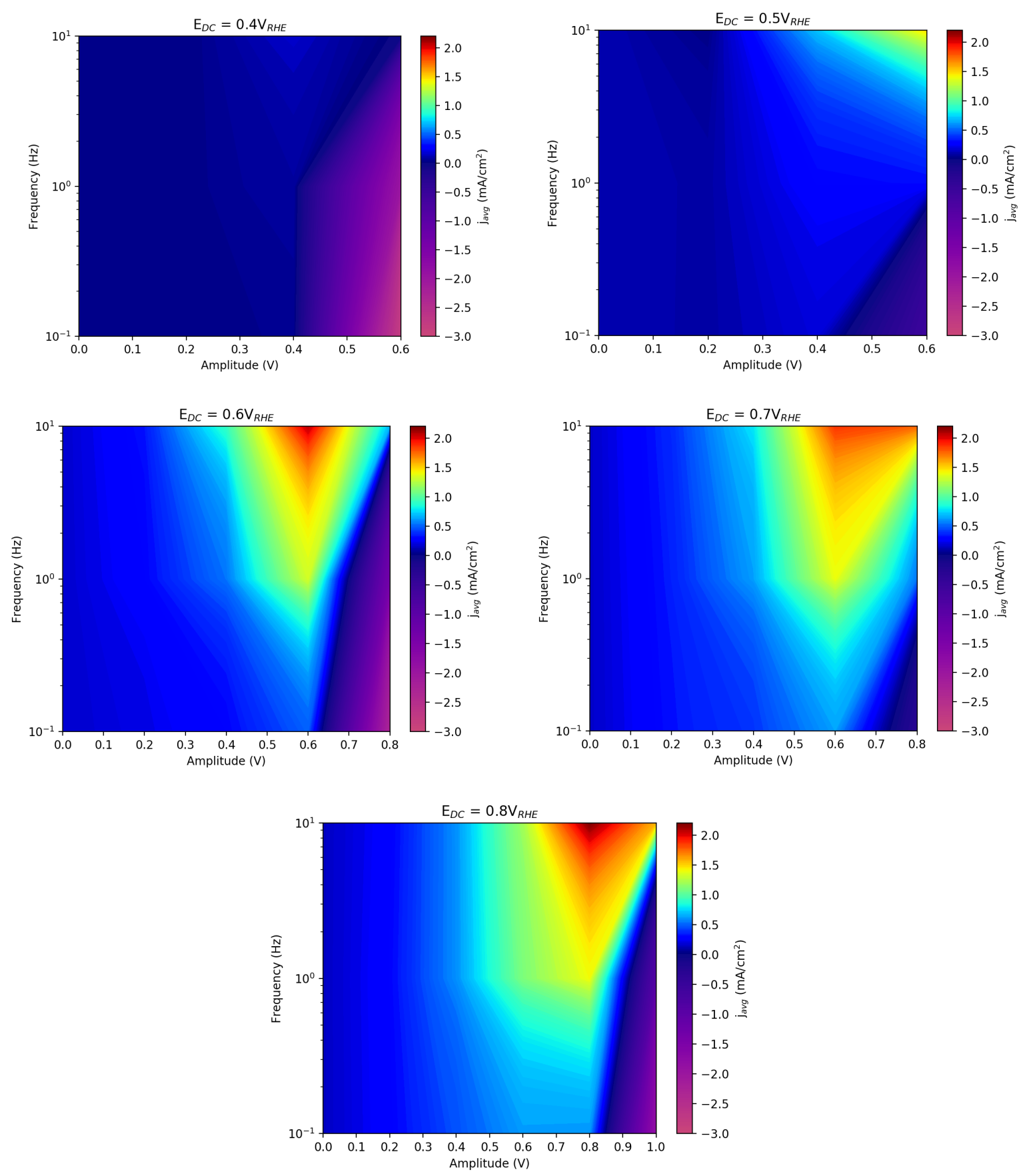

Figure S1. Heat maps showing the averaged current density over the final 60 s of the 300 s rotating disk chronoamperometry experiments shown in Figure 2 in the main text. Negative contributions to current density relate to $\mathrm{H}_{2}$ evolution; the regions of prevalence are shown in Figure S2. 
2. Heat maps showing cycle-averaged currents during the final 60 s of a 360 s experiment in the presence of no formic acid at $\mathrm{E}_{\mathrm{DC}}=0.4-0.8 \mathrm{~V}_{\mathrm{RHE}}$
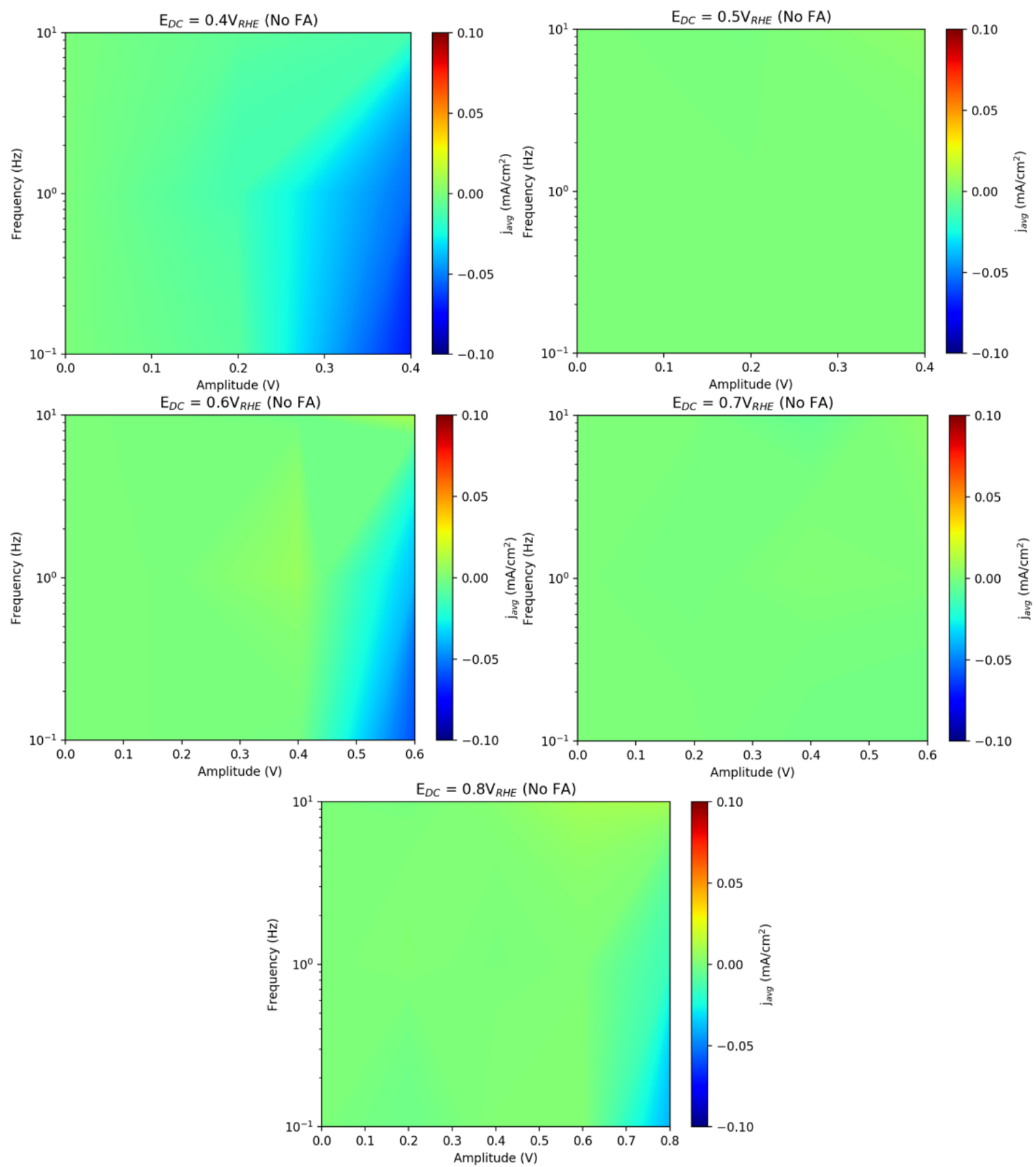

Figure S2. Heat maps showing the averaged current density over the final 60 s of the 300 s rotating disk chronoamperometry experiments run without formic acid present in $0.1 \mathrm{M} \mathrm{HClO}_{4}$. 


\section{Comparison between gas-chromatography predicted current and cycle-averaged currents conducted in a gas-tight batch cell.}

a

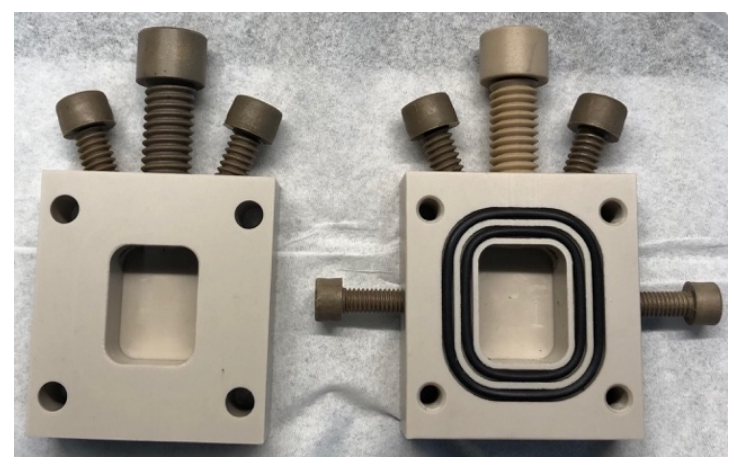

b

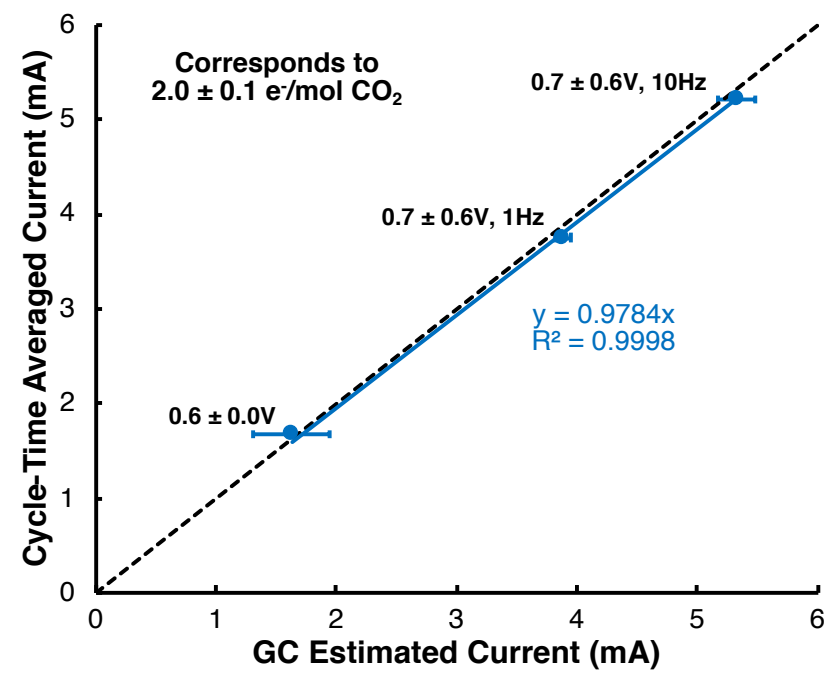

Figure S3. Comparison between gas-chromatography predicted current and cycle-averaged currents conducted in a gas-tight batch cell. (a) Cell image. Note that due to poorer and less-defined mass transport in this cell configuration (compared to rotating disk electrode configuration), the AC-modulated performance enhancements should not be directly compared against those found using the RDE cell. Nonetheless this configuration is sufficient to confirm $\mathrm{CO}_{2}$ is the only product, as the main side reaction to consider would be water splitting. (b) Linearity between $\mathrm{CO}_{2}$ production and net current. The potentiostatic $(0 \mathrm{~Hz})$ case at $0.6 \mathrm{~V}$ was first established to have unit Faradaic efficiency $\left(2.0 \pm 0.1 \mathrm{e}^{-} / \mathrm{CO}_{2}\right)$ using calibration gases. Integrated $\mathrm{CO}_{2}$ signal for each labeled condition (selected to match those found optimal in the RDE experiments) is then converted to an equivalent current based on concentration and carrier gas rate $\left(5 \mathrm{sccm} \mathrm{N} \mathrm{N}_{2}\right)$ and plotted against the measured current, matching the expected slope. All runs performed in $0.25 \mathrm{M}$ formic acid $+0.1 \mathrm{M} \mathrm{HClO}_{4}$ with $\mathrm{Pt}$ wire electrode working electrode, $\mathrm{Pt}$ mesh counter electrode, $\mathrm{Ag} / \mathrm{AgCl}$ reference electrode, and Nafion 211 membrane separating WE/CE chambers. Products were analyzed on a TCD detector. 


\section{Complete experimental results during the cycle-averaged oxidation of formic acid using}

PSEA methods at a variety of $A$ and $f$ values over 3600s

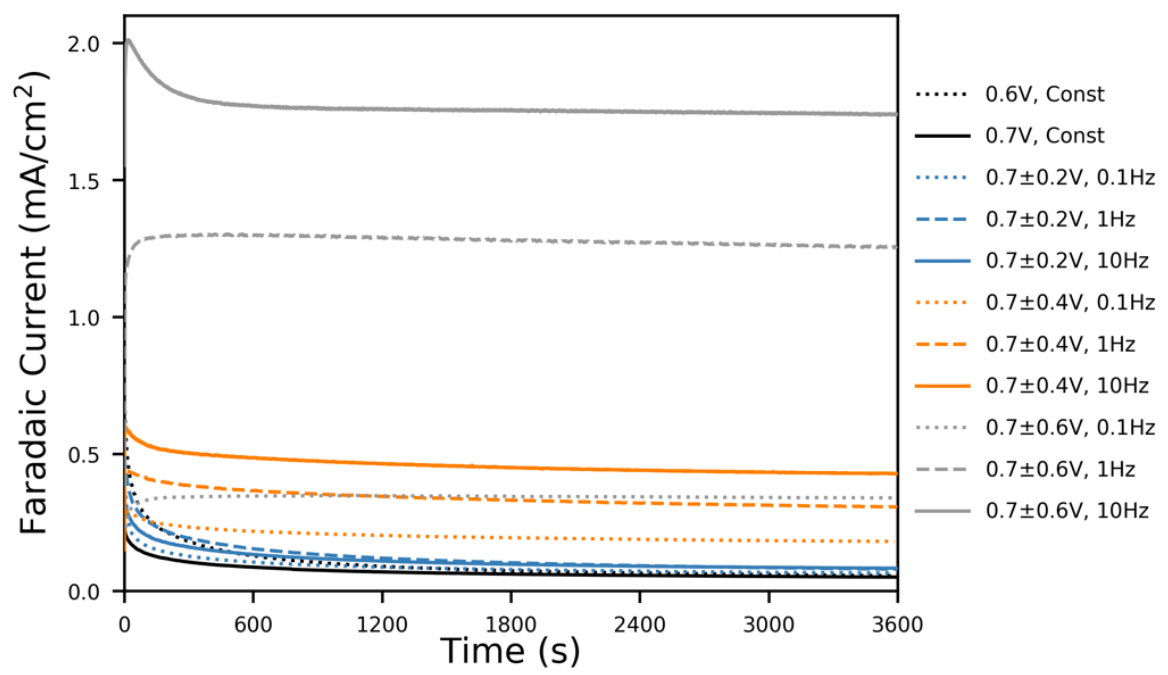

Figure S4. Rotating disk chronoamperometry of polycrystalline Pt RDE tip with $0.1 \mathrm{M}$ formic acid in $0.1 \mathrm{M} \mathrm{HClO}_{4}$ for $3600 \mathrm{~s}$ at $\mathrm{E}_{\mathrm{DC}}=0.7 \mathrm{~V}, f=0.1-10 \mathrm{~Hz}$, and $A=0-0.6 \mathrm{~V}$. Rotation rate $=2500 \mathrm{RPM}$. 


\section{Heat maps showing simulated, cycle-averaged attributes the presence of $0.1 \mathrm{M}$ formic}

acid at $\mathrm{E}_{\mathrm{DC}}=0.4-0.7 \mathrm{~V}_{\mathrm{RHE}}$
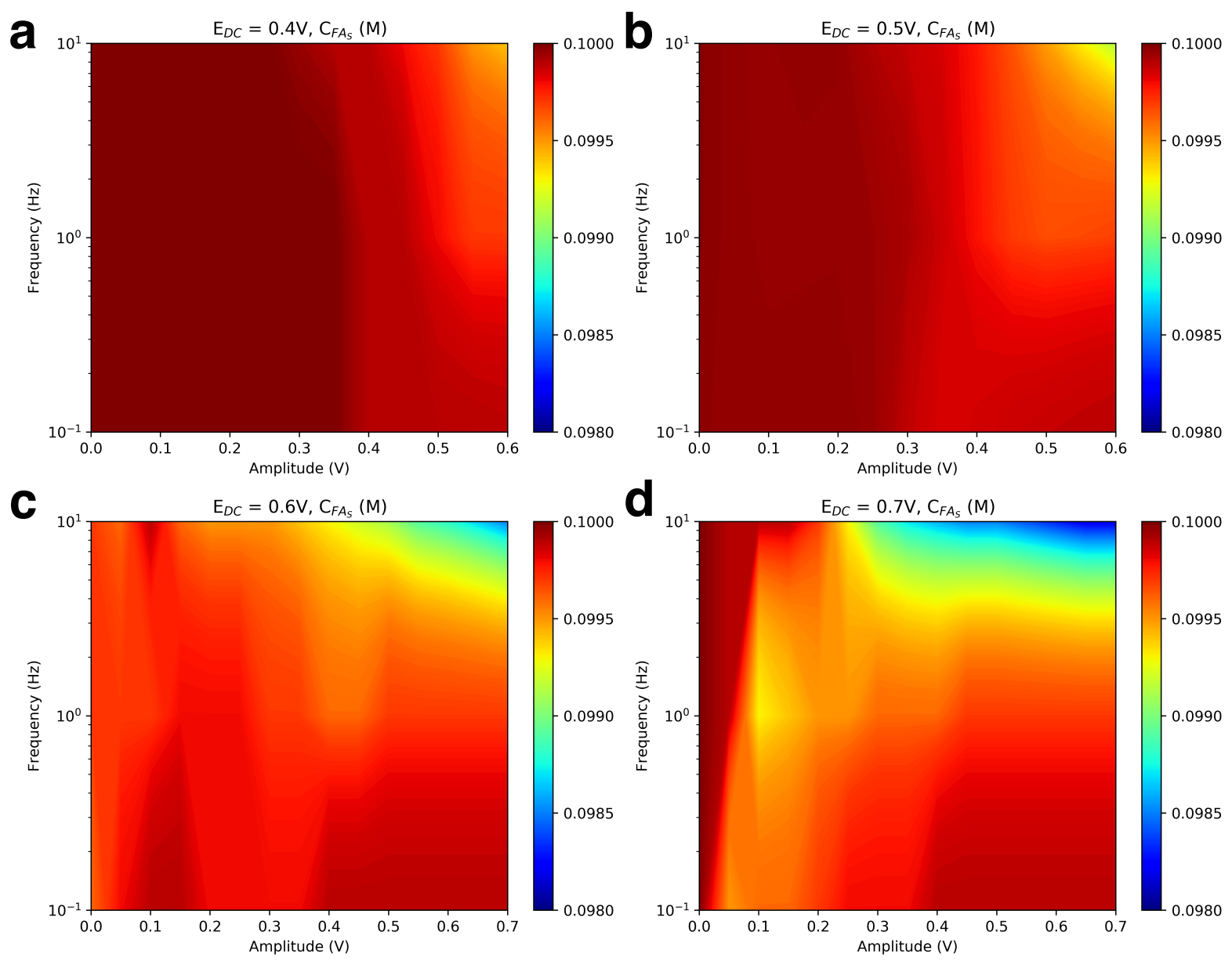

Figure S5. Simulated heat maps showing the cycle-averaged concentration of formic acid near the Pt surface at $\mathrm{E}_{\mathrm{DC}}$ $=$ (a) $0.4 \mathrm{~V}$, (b) $0.5 \mathrm{~V}$, (c) $0.6 \mathrm{~V}$, and (d) $0.7 \mathrm{~V}$ during formic acid oxidation. 

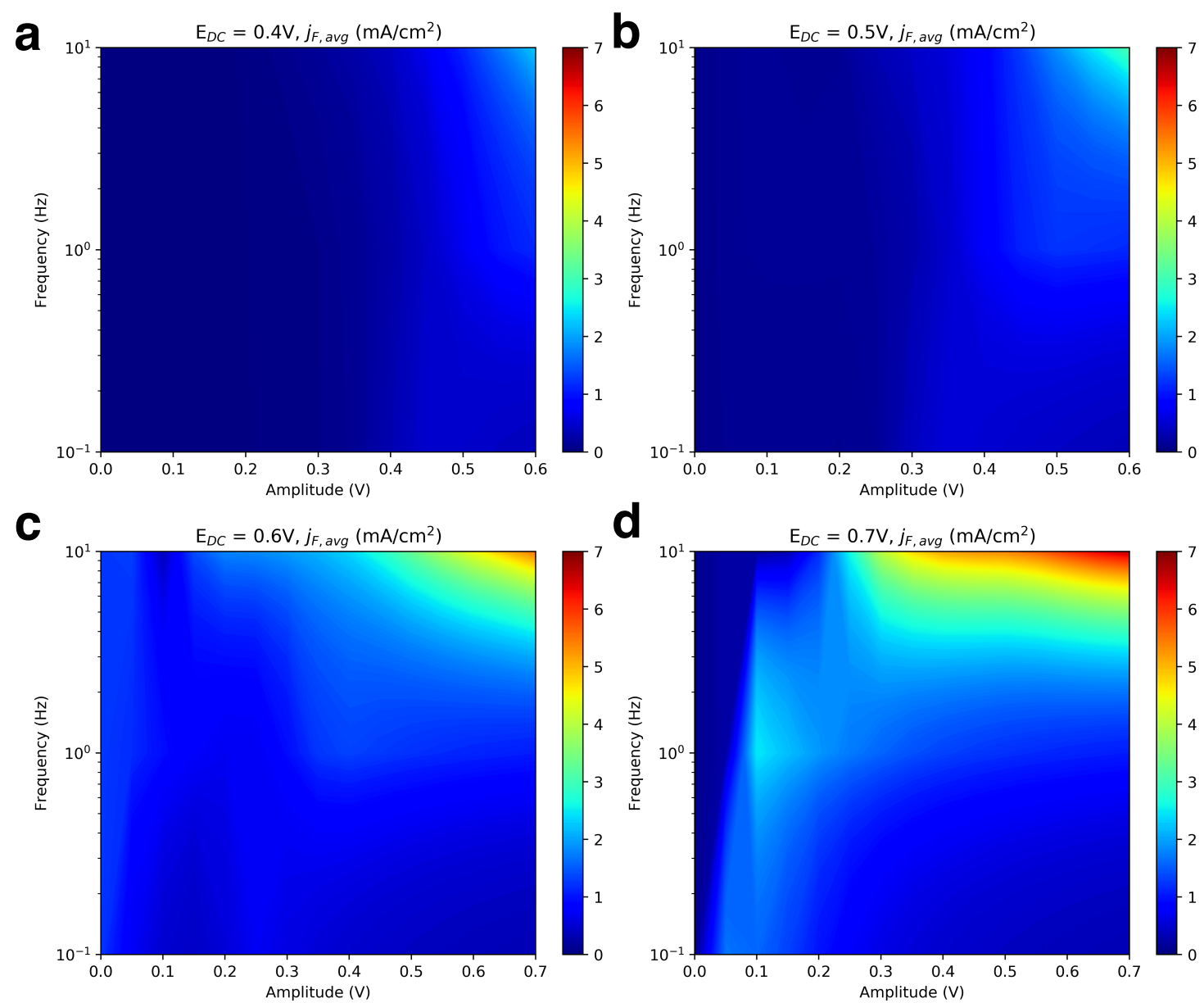

d

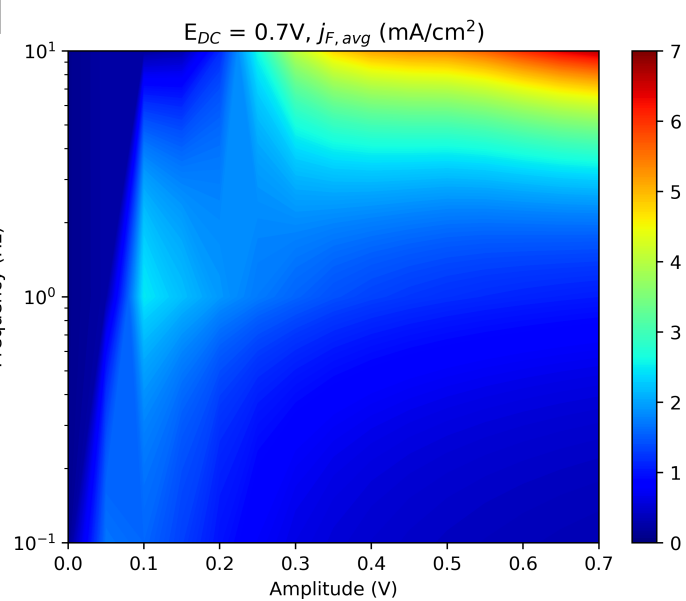

Figure S6. Simulated heat maps showing the cycle-averaged current density during formic acid oxidation at $\mathrm{E}_{\mathrm{DC}}=(\mathrm{a})$ $0.4 \mathrm{~V}$, (b) $0.5 \mathrm{~V}$, (c) $0.6 \mathrm{~V}$, and (d) $0.7 \mathrm{~V}$. 

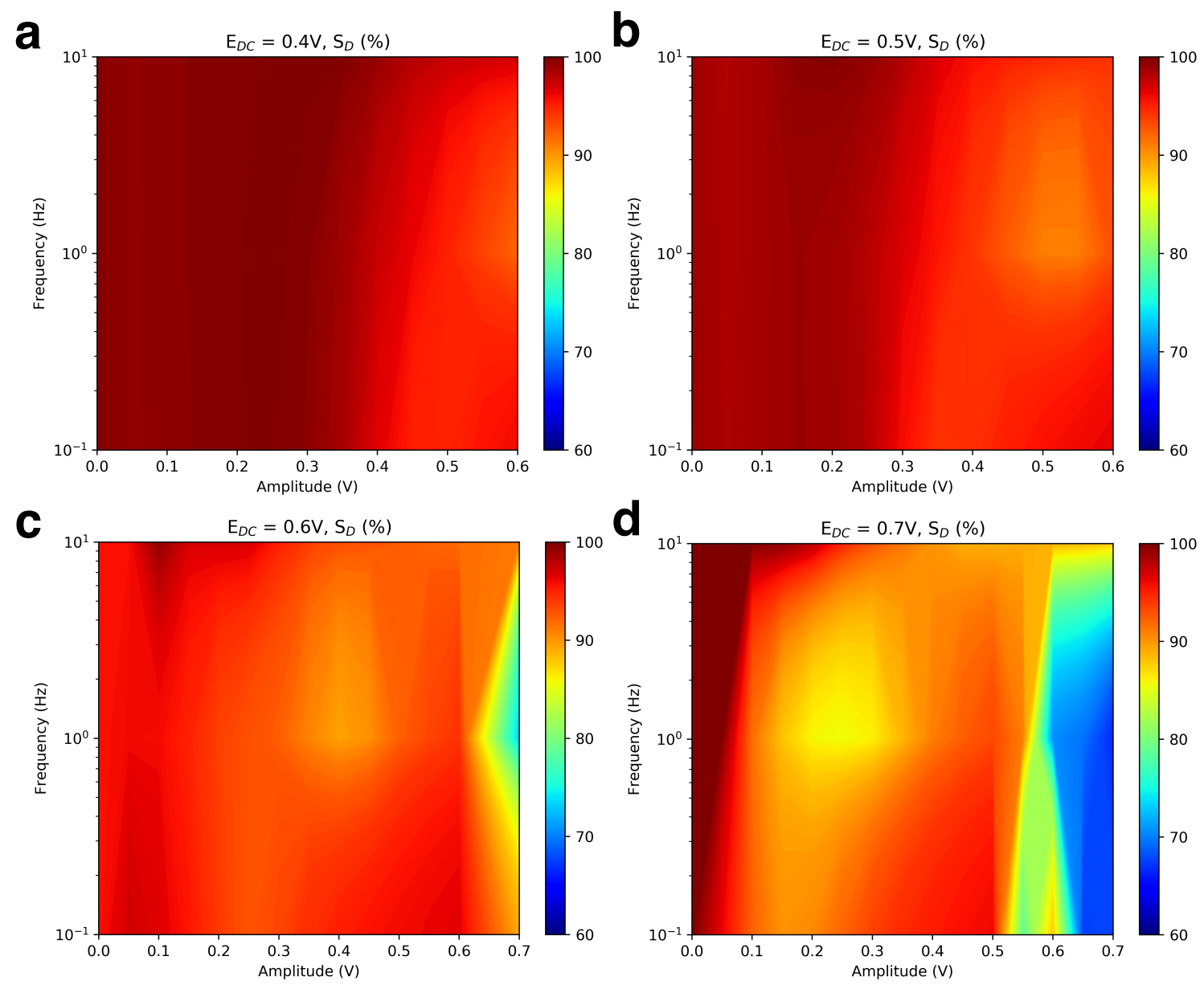

Figure S7. Simulated heat maps showing the cycle-averaged selectivity of formic acid oxidation via the direct oxidation pathway at $\mathrm{E}_{\mathrm{DC}}=$ (a) $0.4 \mathrm{~V}$, (b) $0.5 \mathrm{~V}$, (c) $0.6 \mathrm{~V}$, and (d) $0.7 \mathrm{~V}$. 

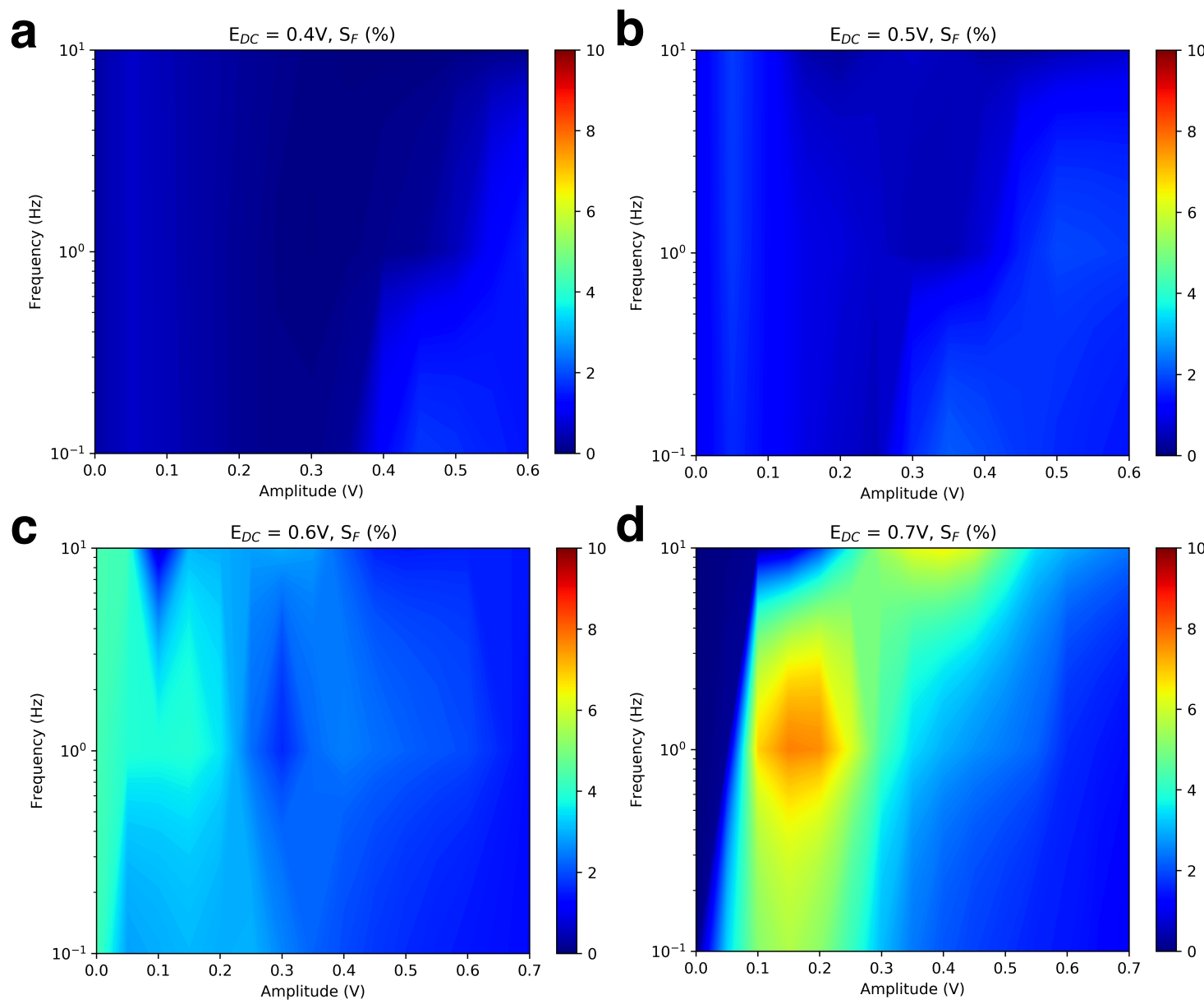

Figure S8. Simulated heat maps showing the cycle-averaged selectivity of formic acid oxidation via the formate oxidation pathway at $\mathrm{E}_{\mathrm{DC}}=$ (a) $0.4 \mathrm{~V}$, (b) $0.5 \mathrm{~V}$, (c) $0.6 \mathrm{~V}$, and (d) $0.7 \mathrm{~V}$. 

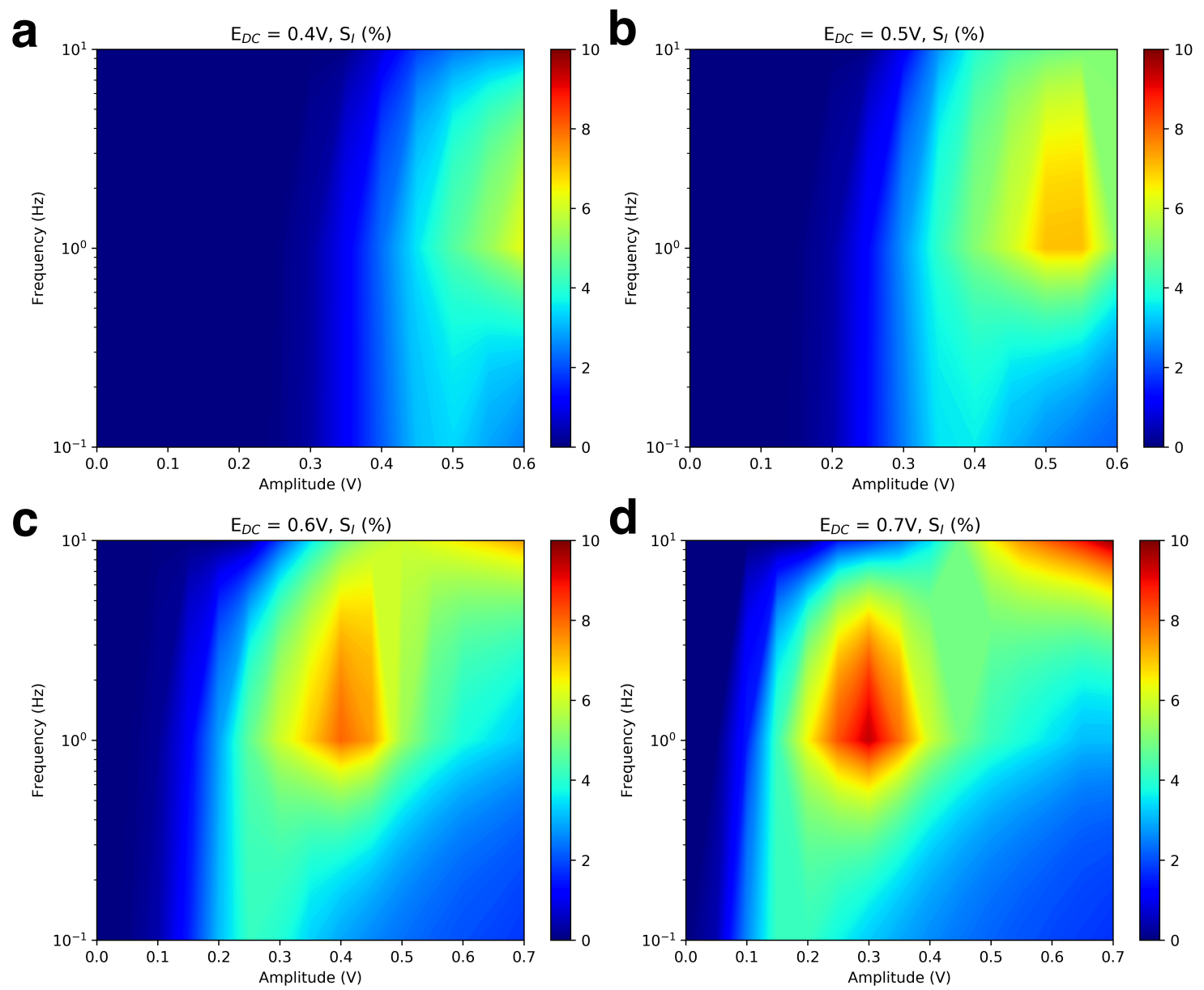

Figure S9. Simulated heat maps showing the cycle-averaged selectivity of formic acid oxidation via the indirect oxidation pathway at $\mathrm{E}_{\mathrm{DC}}=$ (a) $0.4 \mathrm{~V}$, (b) $0.5 \mathrm{~V}$, (c) $0.6 \mathrm{~V}$, and (d) $0.7 \mathrm{~V}$. 

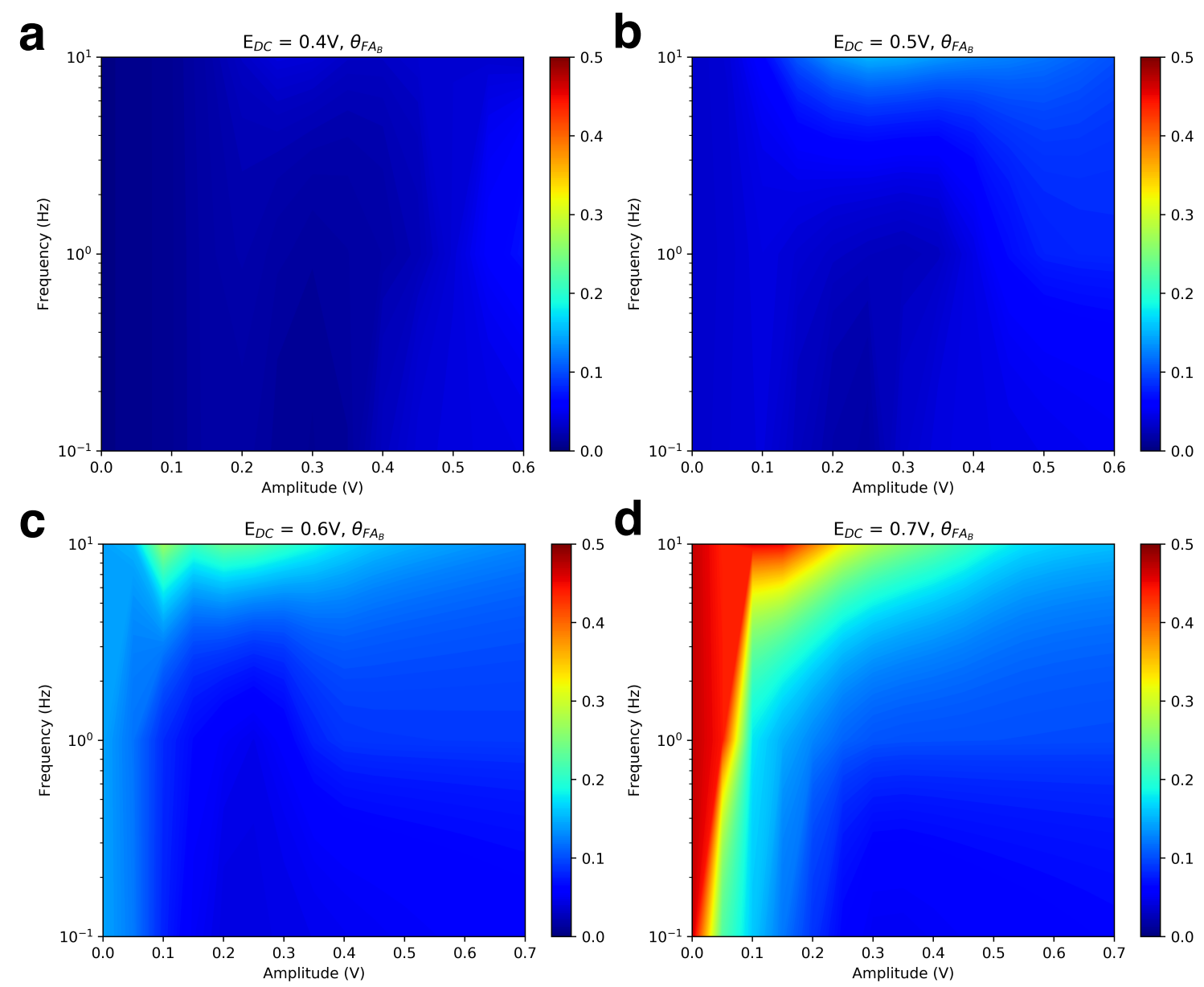

Figure S10. Simulated heat maps showing the cycle-averaged surface coverage of bridge-bound formate during formic acid oxidation at $\mathrm{E}_{\mathrm{DC}}=($ a) $0.4 \mathrm{~V}$, (b) $0.5 \mathrm{~V}$, (c) $0.6 \mathrm{~V}$, and (d) $0.7 \mathrm{~V}$. 


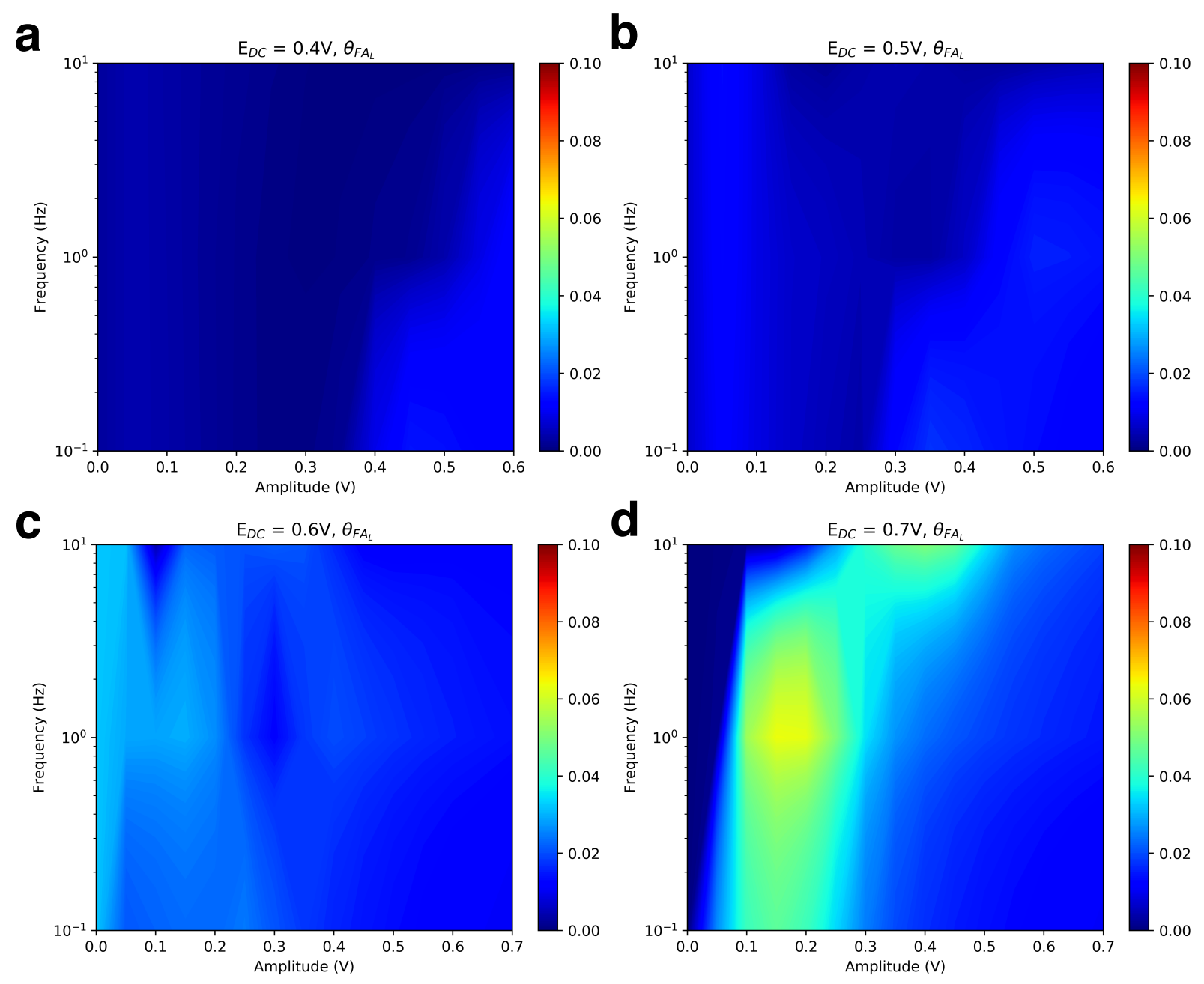

Figure S11. Simulated heat maps showing the cycle-averaged surface coverage of linearly-bound formate during formic acid oxidation at $\mathrm{E}_{\mathrm{DC}}=$ (a) $0.4 \mathrm{~V}$, (b) $0.5 \mathrm{~V}$, (c) $0.6 \mathrm{~V}$, and (d) $0.7 \mathrm{~V}$. 


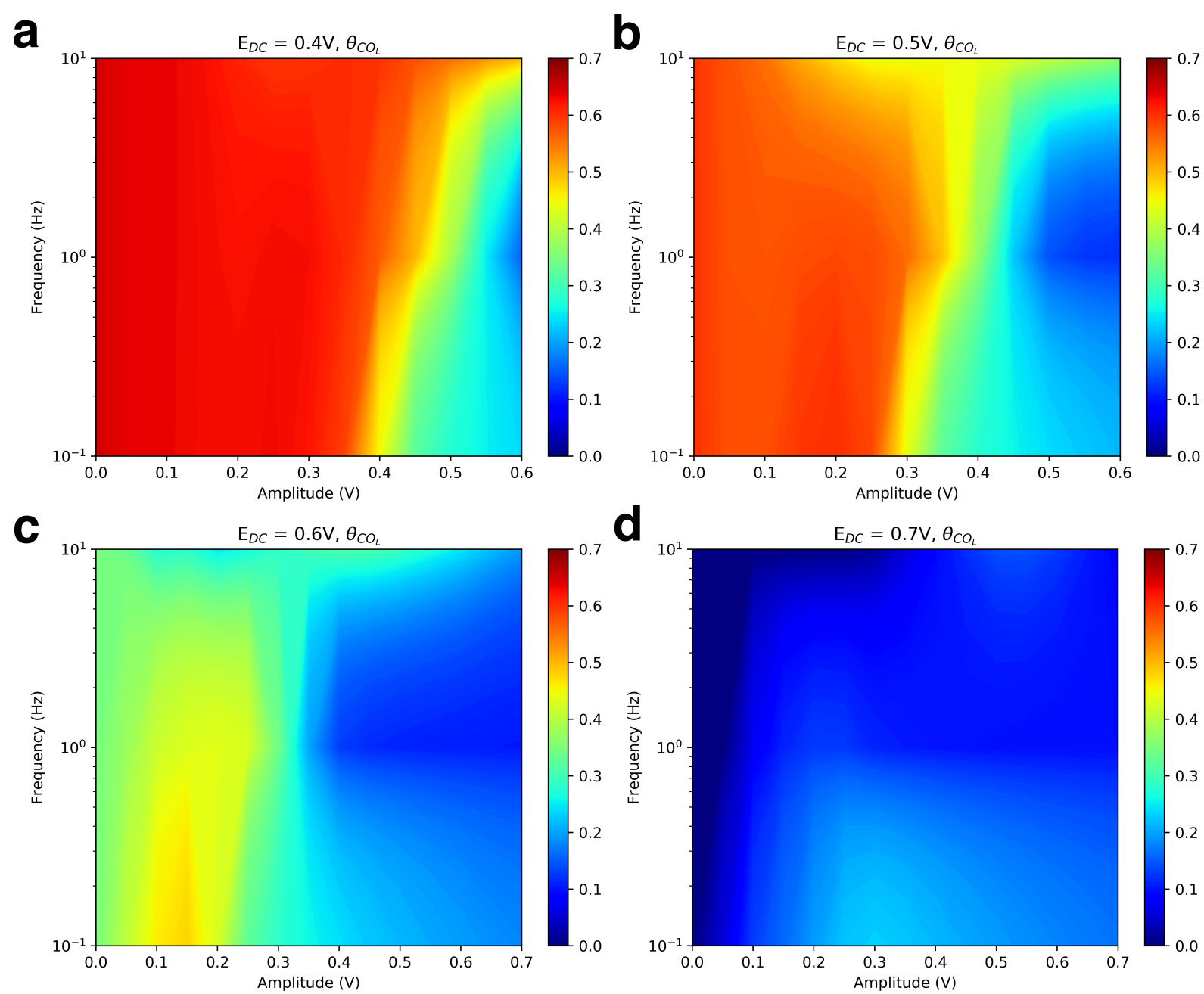

Figure S12. Simulated heat maps showing the cycle-averaged surface coverage of linearly-bound carbon monoxide during formic acid oxidation at $\mathrm{E}_{\mathrm{DC}}=(\mathrm{a}) 0.4 \mathrm{~V}$, (b) $0.5 \mathrm{~V}$, (c) $0.6 \mathrm{~V}$, and (d) $0.7 \mathrm{~V}$. 


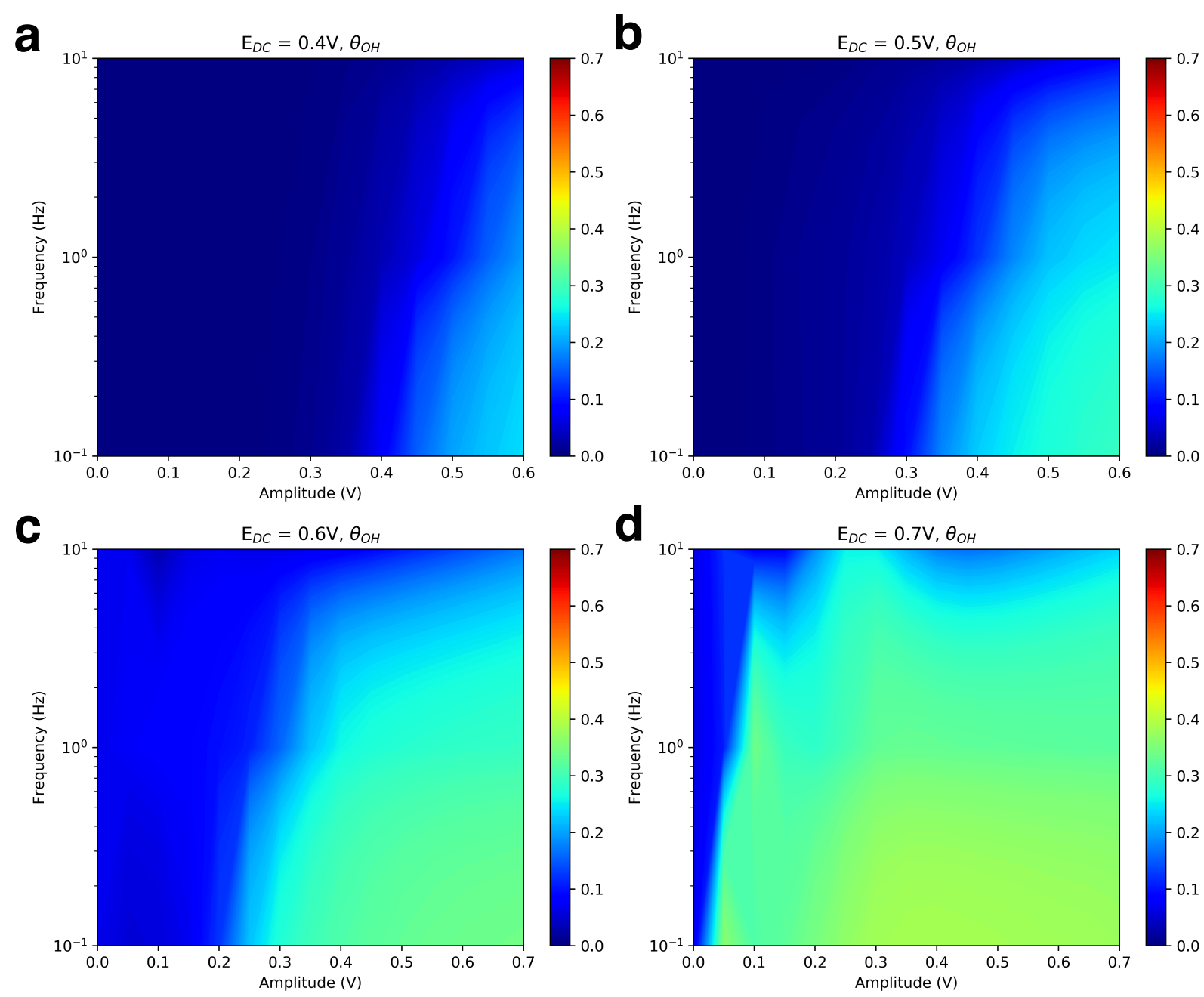

Figure S13. Simulated heat maps showing the cycle-averaged surface coverage of hydroxyl during formic acid oxidation at $\mathrm{E}_{\mathrm{DC}}=(\mathrm{a}) 0.4 \mathrm{~V}$, (b) $0.5 \mathrm{~V}$, (c) $0.6 \mathrm{~V}$, and (d) $0.7 \mathrm{~V}$. 


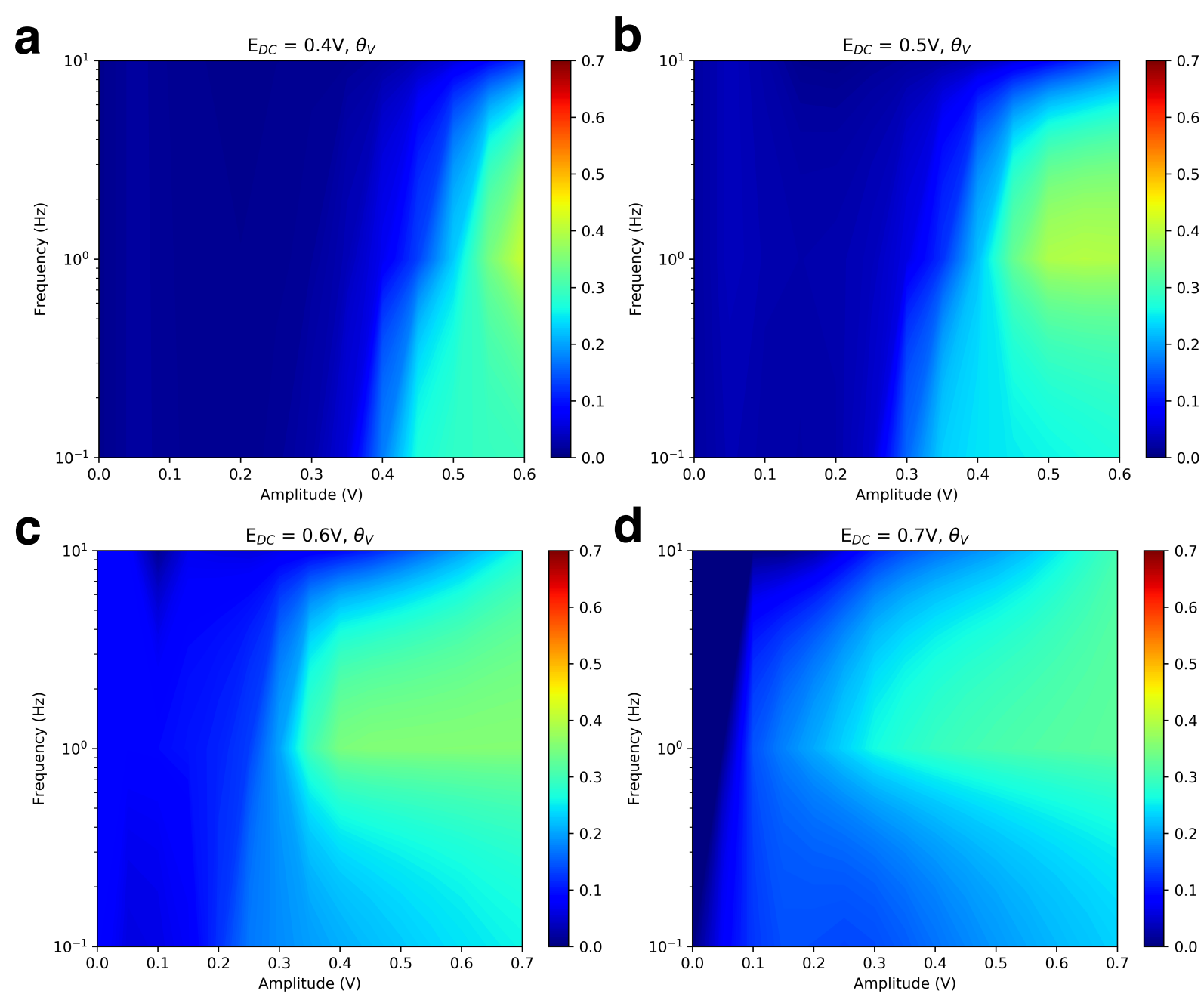

Figure S14. Simulated heat maps showing the cycle-averaged surface vacancy during formic acid oxidation at $\mathrm{E}_{\mathrm{DC}}=$ (a) $0.4 \mathrm{~V}$, (b) $0.5 \mathrm{~V}$, (c) $0.6 \mathrm{~V}$, and (d) $0.7 \mathrm{~V}$. 


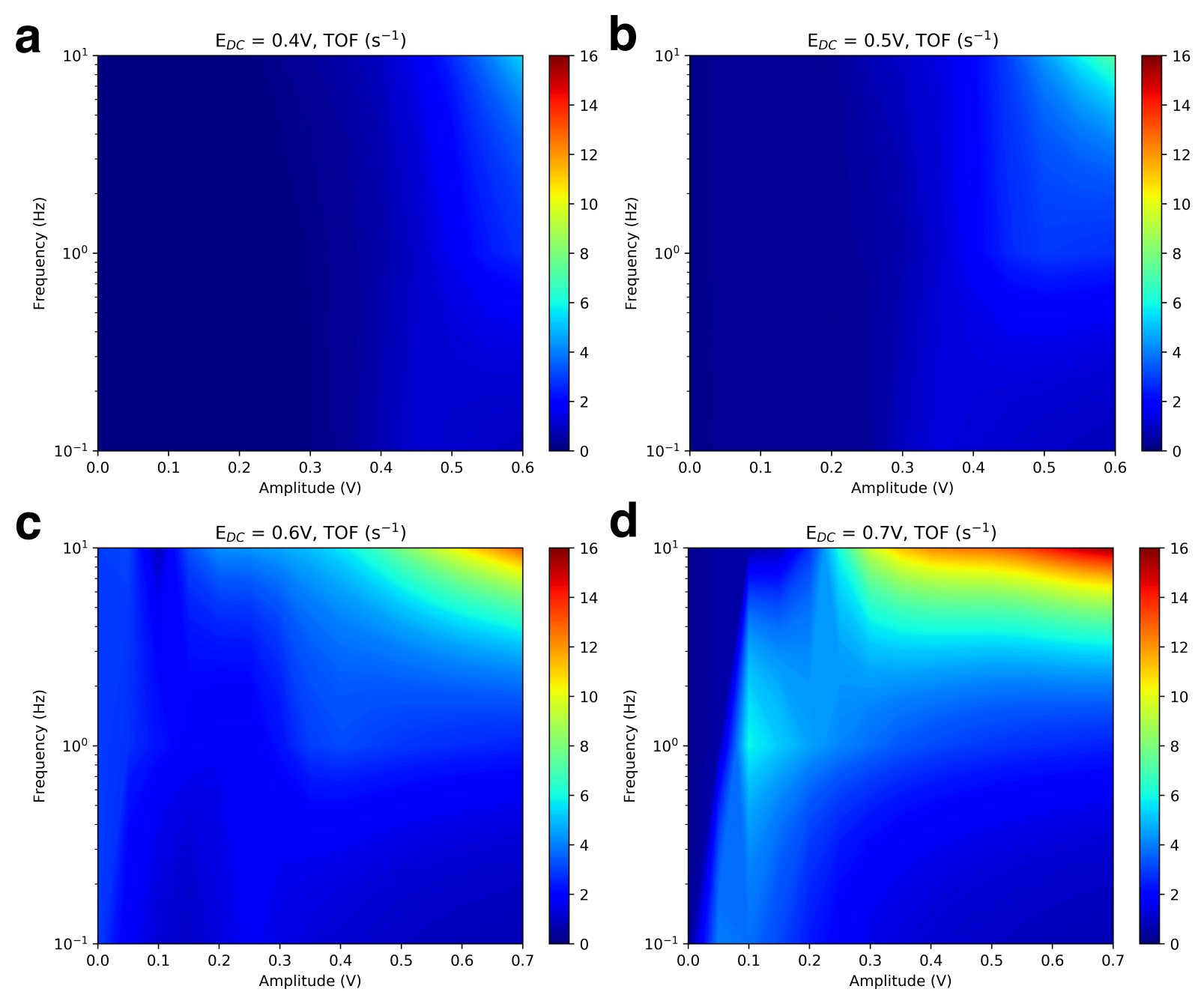

Figure S15. Simulated heat maps showing the cycle-averaged total turnover frequency (TOF) during formic acid oxidation at $\mathrm{E}_{\mathrm{DC}}=(\mathrm{a}) 0.4 \mathrm{~V}$, (b) $0.5 \mathrm{~V}$, (c) $0.6 \mathrm{~V}$, and (d) $0.7 \mathrm{~V}$. 


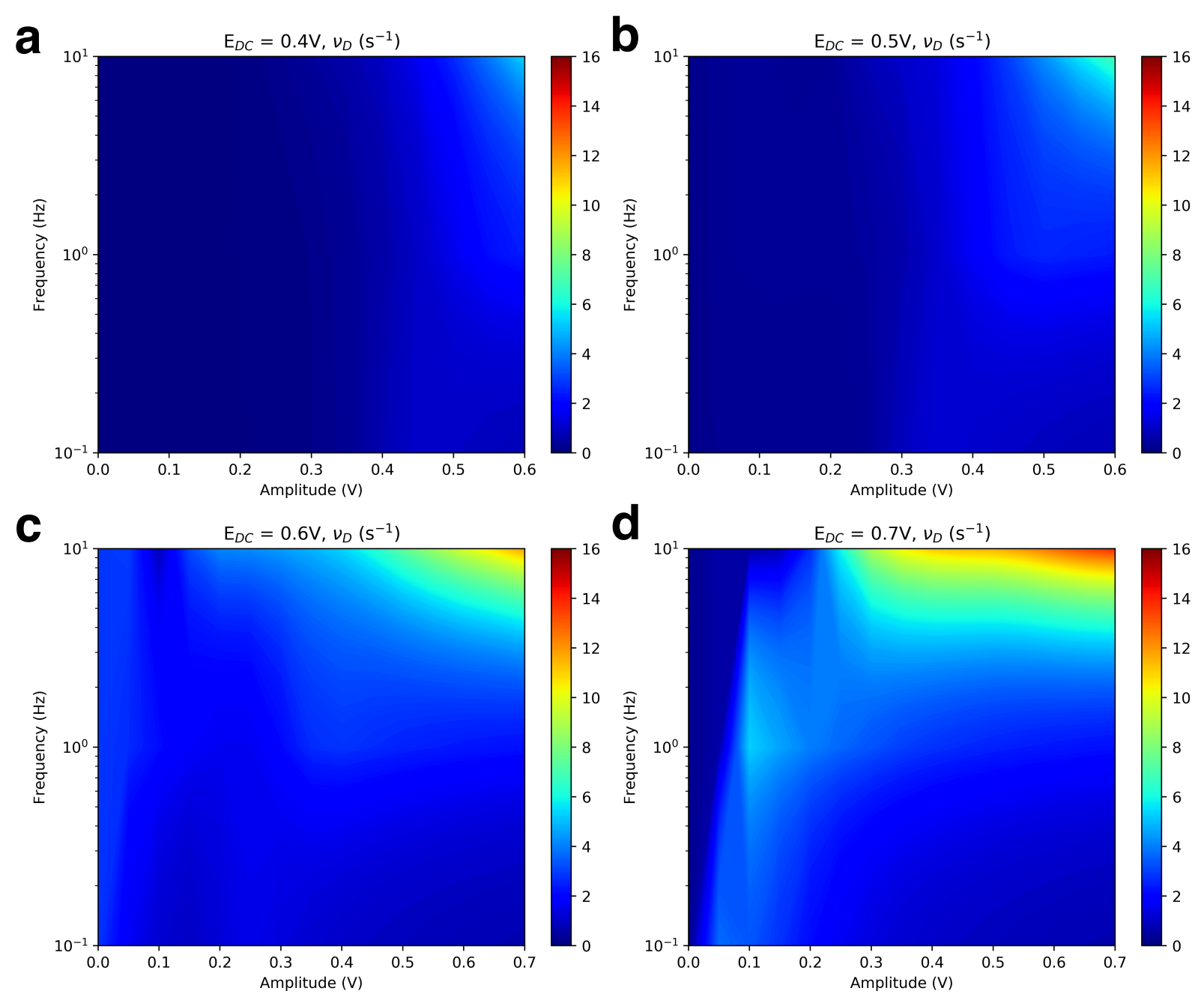

Figure S16. Simulated heat maps showing the cycle-averaged turnover frequency via the direct pathway during formic acid oxidation at $\mathrm{E}_{\mathrm{DC}}=(\mathrm{a}) 0.4 \mathrm{~V}$, (b) $0.5 \mathrm{~V}$, (c) $0.6 \mathrm{~V}$, and (d) $0.7 \mathrm{~V}$. 

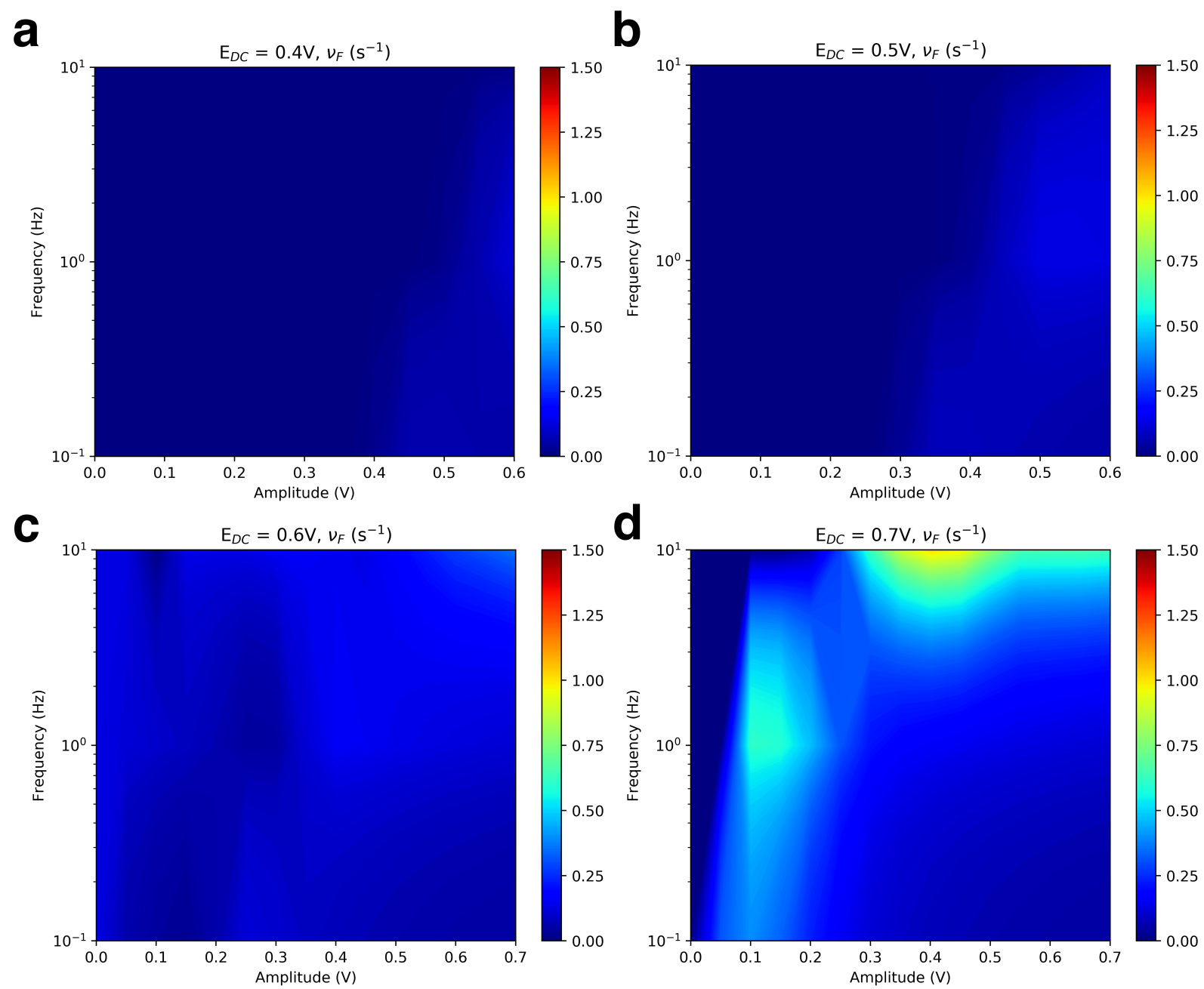

Figure S17. Simulated heat maps showing the cycle-averaged turnover frequency via the formate pathway during formic acid oxidation at $\mathrm{E}_{\mathrm{DC}}=$ (a) $0.4 \mathrm{~V}$, (b) $0.5 \mathrm{~V}$, (c) $0.6 \mathrm{~V}$, and (d) $0.7 \mathrm{~V}$. 


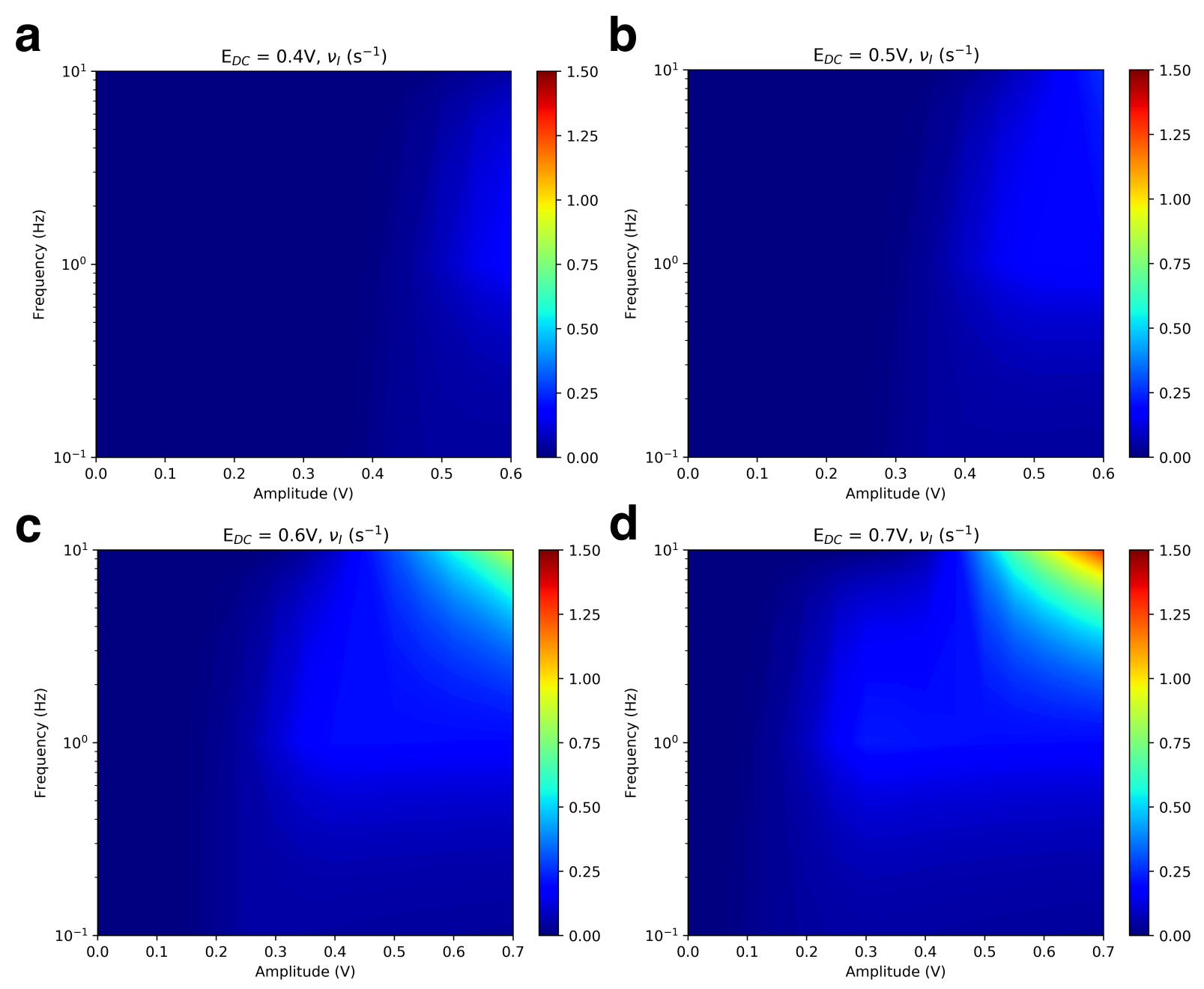

Figure S18. Simulated heat maps showing the cycle-averaged turnover frequency via the indirect pathway during formic acid oxidation at $\mathrm{E}_{\mathrm{DC}}=$ (a) $0.4 \mathrm{~V}$, (b) $0.5 \mathrm{~V}$, (c) $0.6 \mathrm{~V}$, and (d) $0.7 \mathrm{~V}$. 